\title{
Corporate Bond Prices and Idiosyncratic Risk: Evidence from Australia
}

\author{
Victor Fang $^{1, *}$ and Chi-Hsiou D. Hung ${ }^{2}$ \\ ${ }^{1}$ Deakin University, ${ }^{2}$ University of Glasgow
}

\begin{abstract}
In this paper we investigate the bond price effect upon the information arrival of firmspecific idiosyncratic risk. We consider idiosyncratic dispersion and idiosyncratic volatility that capture, respectively, the direction of information and the magnitude of idiosyncratic risk. We find that idiosyncratic volatility does not affect bond prices, while the direction of idiosyncratic risk which reflects the favorable or unfavorable information exhibits impacts on bond prices. Idiosyncratic dispersion in the stock return of a firm in the preceding week, in general, is positively associated with bond price changes in the current week. This effect is most pronounced for firms exhibiting characteristics associated with lower default risk.
\end{abstract}

JEL Classification: G10; G12; G14

Keywords: Idiosyncratic Risk; Idiosyncratic Dispersion; Idiosyncratic Volatility; Corporate Bond Price; Australian Bond Markets

\footnotetext{
* Corresponding author: e-mail: v.fang@ deakin.edu.au, Tel: +61 3 92446919, address: School of Accounting Economics \& Finance, Melbourne Burwood Campus, Deakin University, Australia.
} 


\section{Introduction}

The market of non-government bonds in Australia, unlike many other countries, is significantly larger than the government bond market, reflecting the relatively low Australian public debt as depicted in Figure 1. Debelle (2011) estimates that the ratio of the outstanding amount of non-government bonds to the GDP in Australia is 94\%, in between the $84 \%$ ratio in Germany and the $144 \%$ ratio in the U.S. Despite the important role that the Australian private debt market plays in the economy, this market remains understudied in empirical finance research. In this paper we explore the Australian bond market and contribute to the literature by conducting an anatomy of the relation between bond price changes and idiosyncratic risk.

We distinguish bond price effects of two components of firm-level idiosyncratic risk: idiosyncratic dispersion $\varepsilon_{j, t}$ and idiosyncratic volatility $I V O L_{j, t}$ that contain, respectively, the (positive or negative) sign and the magnitude of the risk. For this purpose, we investigate whether bond price changes are related to idiosyncratic dispersion in the stock return of a firm. We also examine whether firm-level idiosyncratic volatility is accompanied with bond price changes. Using weekly data of bonds and stocks of individual firms in Australia, we provide direct evidence that bond prices are associated with idiosyncratic dispersion, but not with idiosyncratic volatility.

We first obtain idiosyncratic dispersion of a firm using the regression residual from jointly estimating the three-factor model of Fama-French (1993) for average stock returns and the GJR-GARCH model for conditional volatility. We then test whether bond price changes are related to idiosyncratic dispersion in the stock return of a firm. We run 
regressions of bond price changes on firm-specific idiosyncratic dispersion and a set of widely used control variables that measure the economic and market conditions. We apply the Newey-West standard errors to correct for heteroskedasticity and autocorrelation. We also run regressions of bond price changes on firm-specific idiosyncratic volatility and the set of control variables to test whether bond price changes are related to idiosyncratic volatility.

This paper contributes to the literature in the following areas. First, we document important evidence that the direction of idiosyncratic risk is significantly related to changes in the bond price. Our investigation into the bond price effect of the direction of idiosyncratic information surprise about a firm sheds important insights into the dynamics between firm-level idiosyncratic risk and bond prices.

We find that it is the with-direction idiosyncratic risk reflecting the information content affects bond prices, often with a time lag of one week. In contrast, the non-direction magnitude of idiosyncratic risk does not exhibit such an effect. This finding suggests that in Australia bond investors do not appear to be concerned about stock return volatility. Kwan (1996) also argues that the driver of the stock and bond prices is predominantly the firmspecific information related to the mean rather than the variance of the firm's underlying assets. Kwan (1996) documents that stocks returns are negatively correlated with yield changes of bonds issued by the same firm, implying a positive relation between stock returns and bond returns.

In this paper, we further point out the fact that volatility does not preserve the sign of the return variation, and therefore does not convey the information content of the return shock, either to the upside or to the downside. Our use of unexpected return captures the 
direction of firm-specific information, reflecting favorable or unfavorable information to the firm.

A positive unexpected return reveals a favorable signal about the value of the firm's underlying assets. This, in turn, benefits the bond price since it indicates a positive prospect of the firm to meet its debt obligations. In contrast, a negative unexpected return conveys unfavorable firm information about the value of the firm's underlying assets not captured by the market-wide variation in common risk factors. This exerts a negative impact on the bond price since the value of the firm assets may deteriorate, hampering the prospect of covering the firm's debt liabilities.

Our finding of non-contemporaneous bond price changes in respect of the direction of information surprises suggests that bond investors take time to interpret firm-specific information contained in idiosyncratic risk. This is consistent with the finding of Kwan (1996) that stock prices tend to lead bond prices in reacting to information arrivals. Kwan (1996) discusses that some of the firm-specific information is not simultaneously embedded into individual stock and bond prices, which provides the intuition for the lead-lag effect between stock and bond returns. In our paper, we use unexpected return to capture the part of firm-specific information that is not reflected in the expected stock returns. Since expected stock returns reflect all public inform, our specification of unexpected return captures the element of firm-specific information that is not fully impounded into the bond price.

Second, we find a positive relation between the change in the bond price and firmspecific idiosyncratic dispersion of the stock issued by the same firm. In other words, a positive change in the bond price is associated with a positive idiosyncratic dispersion in 
stock returns, whereas a negative change in the bond price is associated with a negative idiosyncratic dispersion. This evidence suggests that price responses of the stock and bonds of the firm are in similar direction with respect to either favorable or unfavorable firmspecific information.

Third, we provide a detailed anatomy of the relation between bond price changes and idiosyncratic dispersion and idiosyncratic volatility by looking into several firm characteristics related to default risk and bond indentures. We find that bond investors of financial institutions that are subject to stringent regulations tend to pay attention to idiosyncratic dispersion. Moreover, the change in the price of the bonds with shorter durations, or issued by firms exhibiting characteristics of higher credit ratings or decreasing leverage ratios is in the same direction as firm-level idiosyncratic dispersion. Overall, our findings suggest that for firms with characteristics exhibiting relatively lower default risk, bond investors pay attentions to the information content of idiosyncratic risk, rather than idiosyncratic volatility.

Our use of a time-series regression examines the extent to which the firm-specific unexpected stock return or idiosyncratic volatility explains the time-series variation in bond returns. Importantly, since our aim is to capture the firm-level idiosyncratic component of returns and volatility, the estimation approach allows us to precisely focus on each of the individual bonds and firms. We are able to correct for heteroskedasticity and autocorrelation in the standard errors for each bond, while accommodating the GARCH type property of time-varying volatility rather than a constant volatility. Moreover, the time-series estimation has the advantage of substantially reducing the noise introduced by 
the large variation in the cross-section of idiosyncratic risk across different bonds and firms.

Campbell and Taksler (2003) use a static volatility as measured by the standard deviation of the regression residuals from a market model, and find that contemporaneous idiosyncratic volatility helps explain the variation in corporate bond yields. ${ }^{1}$ For robustness checks, we also conduct all our tests using the construction of idiosyncratic volatility as in Campbell and Taksler (2003). ${ }^{2}$ The results (not reported for brevity, but available upon request) are quantitatively very similar to what we report in our paper that contemporaneous idiosyncratic volatility generally does not show significant relation with bond returns. $^{3}$

The difference in the overall pattern of our results from those of Campbell and Taksler (2003) mainly reflects the fact that the regression residuals from a market model do not capture the components of the $S M B$ and $H M L$ factors in expected stock returns. Consequently, the static idiosyncratic volatility computed from the market model residuals contains the components of information related to the $S M B$ and $H M L$ factors. Further, in our paper we construct idiosyncratic volatility using the Fama-French three factor model, together with the GJR-GARCH model, and shows that once the other market-wide components in expected stock returns and the asymmetric and time-varying properties of

\footnotetext{
${ }^{1}$ Campbell and Taksler (2003) note that they effectively estimate a market model which imposes restrictions of a zero intercept and a slope coefficient of one, and compute the standard deviation of the residuals to measure volatility.

${ }^{2}$ We thank the anonymous referee for this useful suggestion.

${ }^{3}$ Using the construction of idiosyncratic volatility as in Campbell and Taksler (2003), we further include a one-period lag of idiosyncratic volatility in the regression model. The one-period lag of idiosyncratic volatility only shows significance sporadically, and does not show a consistent pattern of results.
} 
firm-specific volatility are controlled, idiosyncratic volatility, either contemporaneous or with one-period lag, does not show statistically significant relation with bond returns.

The rest of the paper proceeds as follows. Section 2 describes the intuition and motivation and develops the hypothesis. Section 3 presents the methodology. In Section 4 we describe our empirical analyses including the description of our sample. Section 5 presents the empirical results, and Section 6 concludes.

\section{Motivation and Hypothesis}

The theory and evidence demonstrate the relation between firm volatility and corporate bond yields. According to the classic structural model of Merton (1974), corporate debt is a risk-free bond minus a put option written on the value of the firm's assets with the strike price equal to the face value of the debt. This suggests that the corporate bond value is negatively associated with the firm volatility. ${ }^{4}$ Campbell and Taksler (2003) show evidence from the U.S. market that firm-level idiosyncratic volatility captures as much variation in the credit spread as do credit ratings, while systematic or market-wide volatility does not explain corporate bond yields. ${ }^{5}$

\footnotetext{
${ }^{4}$ Other papers that study structural models include Ingersoll (1977), Jones, Mason and Rosenfeld (1984), Longstaff and Schwartz (1995), Elton, Gruber, Agrawal and Mann, (2001), among others. The reduced-form approach, in contrast, assumes exogenously stochastic default probability and recovery rate (See, for example, Jarrow and Turnbull (1995), Duffie and Singleton (1997 and 1999), Duffee (1998) and Longstaff, Mithal and Neis (2005)). The variables considered in these studies, however, are not able to completely explain credit spreads. In fact, these models severely underestimate realized spreads, particularly for investment-grade bonds (Altman and Kishore (1998)). Duffee (1998) finds that yield spreads of callable bonds vary strongly with Treasury rates.

${ }^{5}$ The relation between idiosyncratic risk and asset prices has received a new wave of interests. Campbell, Lettau, Malkiel and Xu (2001), and Irvine and Pontiff (2009) find that idiosyncratic volatility exhibits an upward trend in recent years while the changes in market volatility are transitory. Goyal and Santa-Clara (2003) show that idiosyncratic risk has forecasting power for market returns. Bali, Cakici, Zhe and Yan (2005), however, argue that the results of Goyal et al. are driven by small stocks and are period specific. Fu (2009) and Spiegel and Wang (2005) find a significantly positive relation between idiosyncratic volatility and
} 
In essence, idiosyncratic volatility measures the magnitude of the firm-specific unexpected return. This is because idiosyncratic volatility, i.e., the square root of idiosyncratic variance, shows the degree of variation in stock returns not captured by common risk factors. Crucially, however, volatility does not preserve the sign of the return variation, and therefore does not convey the information content of the return shock, either to the upside or to the downside.

In addition to analyzing the firm variance effect, Kwan (1996) also considers the effect of the mean value of the firm, and studies the relation between the stock return and changes in the bond yield of the same firm. In this study, we further consider whether the unexpected return shock exhibits an association with the price of the bond issued by the same firm. We term idiosyncratic return dispersion for the unexpected return, which measures the content of firm-specific information.

Depending on the direction of the firm-specific unexpected return, bond prices may react differently according to whether the unexpected shock reflects favorable or unfavorable news to the firm. A positive idiosyncratic return dispersion reflects an increase in the stock price not captured by the common movements in the market-wide factors. Intuitively, a positive idiosyncratic variation may indicate a positive shock on the firm's prospect, which reveals a favorable signal about the firm in meeting its debt obligations. To the extent that positive variations in the market value of the firm bring the firm close to meeting its liabilities, bond investors may demand a lower credit spread and trade up the bond price.

the cross-section of expected stock returns, which is contradicting to the finding of a negative relation documented by Ang, Hodrick, Xing and Zhang (2006). Bali and Cakici (2008) find no evidence, however, for a significant relation. 
In contrast, a negative firm-specific idiosyncratic return variation may convey unfavorable information about the firm not captured by the common risk factors. This undermines the prospect of the firm in fulfilling its debt liabilities, and hence affects the bond value issued by the firm. To the extent that negative variations in the market value of the firm may bring the firm close to the default threshold, bondholders may be averse to such negative shocks and sell the bond at hand.

The null hypothesis in this paper is that firm-specific idiosyncratic return dispersion does not exert impacts on individual bonds issued by the same firm. A statistically significant coefficient estimate for idiosyncratic dispersion will indicate that idiosyncratic dispersion exerts influences on bond prices. We include the lagged idiosyncratic dispersion as an explanatory variable since Kwan (1996) documents that stock prices tend to lead bond prices in reacting to the arrival of firm-specific information. We also examine the effect of idiosyncratic volatility on bond prices.

\section{Methodology}

\section{3 .1 Idiosyncratic Dispersion and Idiosyncratic Volatility}

We model the firm expected return using the three-factor model of Fama and French (1993). For modelling the variance process we employ the GJR generalized autoregressive conditional heteroskedasticity (GJR-GARCH) model to capture the asymmetric volatility response to information and time-varying properties of idiosyncratic volatility (see also, Fu (2009)). Specifically, for each stock, we jointly estimate a time-series regression over the entire sample period: 


$$
\begin{aligned}
& r_{j, t}=\alpha_{j}+\beta_{j} r_{m, t}+s_{j} S M B_{t}+h_{j} H M L_{t}+\varepsilon_{j, t} ; \varepsilon_{j, t} \sim N\left(0, \sigma_{j, t}^{2}\right) \\
& \sigma_{j, t}^{2}=\omega_{j}+\gamma_{j} \varepsilon_{j, t-1}^{2}+\gamma_{j}^{-} \varepsilon_{j, t-1}^{2}+\vartheta_{j} \sigma_{j, t-1}^{2}
\end{aligned}
$$

where $r_{j, t}$ is the excess stock return of firm $j$ at time $t, r_{m, t}$ is the excess return on the value-weighted market portfolio which we proxy by Australian All Ordinary Index (AOI),

$\alpha_{j}$ is the intercept and $\beta_{j}$ is the sensitivity of the firm to the market index. The coefficients $S_{j}$ and $h_{j}$ are the loadings on the size factor $S M B$ and the value factor $H M L$, respectively. The details on the $S M B$ and $H M L$ factors pertaining to the Australian stock market are in Sections 3. The residual term $\varepsilon_{j, t}$ is assumed to follow a normal distribution with a mean of zero and the conditional variance of $\sigma_{j, t}^{2}$. In (2) $\omega_{j}$ is the intercept, $\gamma_{j}$ is the coefficient for the variance of the residual, $\gamma_{\bar{j}}$ captures the sensitivity on negative shocks in the residual variance and $\vartheta_{j}$ is the loading on the conditional variance estimate at time $t-1$. In the next sub-section we detail our test framework where we specify idiosyncratic dispersion by $\varepsilon_{j, t}$ and describe the computation of idiosyncratic volatility based on $\sigma_{j, t}^{2}$.

\subsection{The Regression Models}

To examine the effect of bond price changes in respect of firm-specific information, we first run the regression of bond price changes on idiosyncratic dispersion together with the control variables including the level and the slope of the term structure and the liquidity premium of corporate bonds relative to Treasury bonds following Campbell and Taksler (2003).

Specifically, for each bond issued by firm $j$ in an analysis, we run a regression over the entire sample period: 
$B R_{i, j, t}=\alpha_{0}+\alpha_{1} B I n d_{t}+\alpha_{2} L E V E L_{t}+\alpha_{3} S L O P E_{t}+\alpha_{4} L I Q_{t}+\alpha_{5} \varepsilon_{j, t}+\alpha_{6} \varepsilon_{j, t-1}+\mu_{i, j, t}$

here $B R_{i, j, t}$ is the $\log$ price return of bond $i$ issued by firm $j$ at time $t, B \operatorname{In} d_{t}$ is the log price return of Australian bond index, $L E V E L_{t}$ is the level of the term structure which we proxy by the 5-year Treasury bond rate, $S L O P E_{t}$ is the slope of the term structure which we use the difference between the 10-year and 3-year Treasury bond rates, $L I Q_{t}$ captures the liquidity premium for which we use the difference between the 90-day bank bill offer rate and the 13-week Treasury yield (see, for example, In, Brown and Fang (2003)), $\varepsilon_{j, t}$ is idiosyncratic dispersion for firm $j$ estimated from (1), $\varepsilon_{j, t-1}$ is the lagged idiosyncratic dispersion at time $t-1$ and $\mu_{i, j, t}$ is the error term. We apply the Newey-West standard errors to correct for heteroskedasticity and autocorrelation in the residual.

For each bond issued by firm $j$, we obtain the parameter estimates in (3) for the intercept and the slope coefficients $\alpha_{k}, k=[0,1, \ldots, 6]$. Following Collin-Dufresne, Goldstein and Martin (2001), we calculate the average intercept $\alpha_{0}$ and the slope coefficients $\alpha_{1}, \ldots \alpha_{6}$ across all the $N$ bonds $(i=1,2, \ldots, N)$ in the analysis as:

$$
\alpha_{k}=\frac{1}{N} \sum_{i=1}^{N} \alpha_{i, k} \quad \text { for } k=0,1, \ldots 6
$$

where $N$ is the number of bonds in the analysis. We compute the $t$-statistic for each of the parameters $\alpha_{k}$ as the mean of the parameter divided by its standard error,

$$
t_{\alpha_{k}}=\frac{\alpha_{k}}{s t d\left(\alpha_{k}\right) / \sqrt{N}}
$$


where $\operatorname{std}\left(\alpha_{k}\right)$ is the standard deviation of $\alpha_{k}$ of the bonds.

We test whether the slope coefficient estimate $\alpha_{5}$ on idiosyncratic dispersion $\varepsilon_{j, t}$ is significantly different from zero. We also run the following regression to examine the effect of idiosyncratic volatility on bond price changes:

$B R_{i, j, t}=\beta_{0}+\beta_{1} \operatorname{BInd}_{t}+\beta_{2} L E V E L_{t}+\beta_{3} S L O P E_{t}+\beta_{4} L I Q_{t}+\beta_{5} I V O L_{j, t}+\beta_{6} I V O L_{j, t-1}+\theta_{i, j, t}$

where $I V O L_{j, t}$ is the conditional idiosyncratic volatility of firm $j$ at time $t$ which is the square root of the estimated conditional variance of the GJR-GARCH model in (2), i.e., $I V O L_{j, t}=\sqrt{\sigma_{j, t}^{2}}$. IVOL $L_{j, t-1}$ is the lagged idiosyncratic volatility at time $t-1$.

\section{Data and Sample Description}

As in Debelle (2011), Figure 2 shows that the Australian debt market has grown over time but the development of the market has not been uniform. The financial institutions have the largest share of issuance over the past two decades. The asset-backed issuance grew rapidly for some time but the growth has been severely affected by the recent financial crisis. In recent years there has been a growing trend of the 'Kangaroo' bonds, i.e., the Australian dollar denominated bonds that are issued by non-residents. Other corporate issuances have grown steadily over the last two decades.

Our empirical analysis of firm specific idiosyncratic risk on bond prices faces a substantial data constrain. Creighton et al. (2007) point out that corporate bonds are not traded in a centralized exchange, making it difficult for obtaining complete data on daily bond prices. Since UBS Australia All Composite Bond Index is widely used as a 
benchmark for the Australian bond funds, we choose the sample of non-government bonds from the constituents of the UBS Bond Index. Within the UBS Australian Composite Bond Index there are 147 issuers and 337 issues. Of these issuers, corporates category ${ }^{6}$ contributes $79 \%$ to the index. The rest of the issuers are Commonwealth government (7\%), semi-government (5\%) and mortgage/asset backed (9\%). To be included in our analysis, we impose the following criteria to select the corporate bonds that are in the UBS Bond Index:

i) Issuers must be locally incorporated and listed on the Australian Stock Exchange.

ii) Issuers must issue straight debt bonds that pay fixed coupons.

iii) Bonds must not be convertible, callable or puttable since these features tend to confound the relation between asset information and the bond price. ${ }^{7}$

As a result, our final sample consists of a total of 117 bonds. The weekly corporate bond prices are collected from Datastream over the period from July 1998 to June 2010. The 3-year, 5-year and 10-year Treasury bond rates, the 90-day bank bill offer rate and the 13-week Treasury yield from the Reserve Bank of Australia website (www.rba.gov.au).

Table 1 shows the industry classifications and credit ratings of our bond sample. We classify the sample into 6 industry sector groups according to global industrial classification sectors (GICS): Consumer Staples, Energy, Financial, Industrial, Materials and Utility, each containing 18, 3, 81, 9, 3 and 3 bonds, respectively. In terms of the rating distribution of the bonds, there are 53 AA-rated bonds, 46 A-rated bonds. Lastly there are $14 \mathrm{BBB}$ bonds and $4 \mathrm{BB}$ bonds in our sample.

\footnotetext{
${ }^{6}$ This category consists of mostly investment grade corporate issuers.

${ }^{7}$ Jones et al. (1984) and Duffee (1998) argue that callable bonds and straight bonds react differently to the same term structure of interest rates.
} 
Table 2 reports descriptive statistics of the bond sample. Of the 117 bonds, 25 bonds pay a coupon rate less than $6 \%, 67$ bonds pay between $6 \%$ and $7 \%$ and the other 25 bonds pay more than $7 \%$. More than a half of the sample bonds ( 65 bonds) have maturities falling within 4 to 6 years, 20 bonds have maturities between 1 and 3 years, and 32 bonds have maturities equal to or longer than 7 years. We compute weekly bond returns using the data of weekly closing prices.

We also obtain weekly returns of individual stocks and the Australian All Ordinary Index from Datastream. In order to construct the $S M B$ and $H M L$ factor portfolios for the Australian stock market, we collect all stocks traded in the Australian stock market. We include both listed and delisted firms to mitigate the survivorship bias, but exclude all noncommon equities and companies listed outside of the domestic exchange ${ }^{8}$. To be included in the analysis, a stock must have both return and market value data for the respective analysis period. At the end of 2010 the sample covers 411 firms in total. Following Fama and French (1993), in each year from July 1998 to June 2010 we rank all stocks according to their market values and then use the median of firm size to split the sample into two groups, small and big ( $\mathrm{S}$ and $\mathrm{B}$ ). Each of the two size groups are then broken down into three book-to-market equity groups based on the breakpoints for the bottom 33\% (Low), middle 34\% (Medium) and top 33\% (High) of the ranked value of the B/M ratio.

The procedures result in 6 portfolios $(\mathrm{S} / \mathrm{L}, \mathrm{S} / \mathrm{M}, \mathrm{S} / \mathrm{H}, \mathrm{B} / \mathrm{L}, \mathrm{B} / \mathrm{M}, \mathrm{B} / \mathrm{H})$ from the intersections of the two size and three $\mathrm{B} / \mathrm{M}$ groups. The $S M B$ factor is the difference

\footnotetext{
${ }^{8}$ We are careful in screening the sample using the suggestion in Ince and Porter (2006). We check company names to help verify their types. We also identify geographical base, traded exchange name and the traded currency for the common shares of each company. We remove those records of padded zero returns at the end of each stock's history.
} 
between the average returns on the three small-stock portfolios ( $\mathrm{S} / \mathrm{L}, \mathrm{S} / \mathrm{M}$ and $\mathrm{S} / \mathrm{H})$ and the average returns on the three big-stock portfolios $(\mathrm{B} / \mathrm{L}, \mathrm{B} / \mathrm{M}$ and $\mathrm{B} / \mathrm{H})$. The $H M L$ factor is the difference between the average returns on the two high $\mathrm{B} / \mathrm{M}$ portfolios $(\mathrm{S} / \mathrm{H}$ and $\mathrm{B} / \mathrm{H})$ and the average returns on the two low $\mathrm{B} / \mathrm{M}$ portfolios ( $\mathrm{S} / \mathrm{L}$ and $\mathrm{B} / \mathrm{L})$.

\section{Empirical Results}

While we note earlier a caveat on the sample of bonds in Australia, the overall result from this study shows consistently that the bond returns are essentially not affected by the idiosyncratic volatility of stock returns but significantly influenced by the idiosyncratic dispersion.

\subsection{All Issuers}

We first estimate equations (3) and (6) for all the sample firms. As shown in the first column of Table 3, the bond index, the level of the term structure and the liquidity premium are highly significant. As expected, the level of the term structure is inversely associated with bond price changes, and the liquidity premium is positively associated with bond price changes.

Importantly, the effect of the lagged idiosyncratic dispersion $\varepsilon_{j, t-1}$ on the bond price one week after information arrival is positive and highly significant at the $1 \%$ level. The result indicates that the lagged idiosyncratic dispersion is of significant importance to bond investors, both economically and statistically. An increase of $1 \%$ in the weekly idiosyncratic dispersion on a firm's common stock leads to an increase of 6 basis points in 
the firm's bond price in the following week. The coefficient estimate for the firm-specific idiosyncratic dispersion $\varepsilon_{j, t}$ is positive, albeit statistically insignificant. These results suggest that bond prices respond to information contained in the idiosyncratic dispersion in the same direction, which is statistically significant with a lagged interval of one-week. Creighton et al. (2007) also document similar results, and report that the bond spread widens on the day after the downgrade announcement. They interpret the delayed adjustment to bond spread as being caused by either the inability of the Australian bond markets in absorbing new information immediately or by the difficulty in obtaining accurate daily data on bond spreads.

The second column of Table 3 reports the results of tests that examine whether idiosyncratic volatility exerts effects on bond price changes as in equation (6). The pattern of results on the bond index, the level and slope of the term structure, and the liquidity premium remain the same as in the first column.

In contrast to the results reported for using the idiosyncratic dispersion, we find that the non-systematic variation in the firm's stock return as measured by idiosyncratic volatility, either contemporaneous or at a one-week lagged interval, does not show any significant effect on bond price changes. The results show that bond prices are sensitive to the direction of information content, but not the non-sign variation of the firm-specific idiosyncratic risk. 


\subsection{Issuer Type}

Financial institutions are the dominant issuers in Australian bond markets (81 out of 117 bonds in the sample) and, in general, have more complex capital structures than nonfinancial institutions. For example, the government requires banks to maintain a minimum capital amount equivalent to 8 percent of total risk-adjusted assets related to their credit risk. The greater the bank's credit risk, the greater is the required minimum capital. In addition, bonds that have maturity periods longer than 5 years can be classified as supplementary capital. Thus, by issuing bonds, the banks in Australia are able to increase their capital at a lower cost. Another reason why the financial institutions are the dominant issuers is that over the last two decades, demand for credit outpaced the growth in deposits. As a consequence, the banks need to access the wholesale funding markets to support the growth in lending. In addition, superannuation funds tend to invest in wholesale bank papers (Debelle, 2011). We separately investigate whether changes in bond prices of financial institutions and non-financial institutions are associated with the idiosyncratic dispersion and idiosyncratic volatility.

Panel A of Table 4 shows the results for financial firms. The lagged idiosyncratic dispersion has a positive coefficient estimate which is significant at the $1 \%$ level, while contemporaneous idiosyncratic dispersion is statistically insignificant. This suggests that the idiosyncratic dispersion, brings a non-immediate significant effect on bond prices of financial firms.

The second column in Panel A of Table 4 shows that idiosyncratic volatility and its lagged term are insignificant, suggesting that bond investors of financial firms do not 
respond to the non-sign magnitude of idiosyncratic risk. These maybe because financial institutions are subject to capital adequacy requirements and have high credit ratings, and thus are able to sustain public confidence on their financial stability.

Panel B of Table 4, for non-financial firms, shows that neither the idiosyncratic dispersion nor its lagged term exhibits significant influences on bond price changes. Likewise, both the contemporaneous and the lagged idiosyncratic volatilities do not carry statistically significant effects on bond prices.

These results show that bond prices of financial and non-financial firms exhibit different relations with firm-specific information. That is, an increase in the idiosyncratic dispersion on a financial firm's equity in one week is accompanied by an increase in the firm's bond price in the next week. The information content of a financial firm reflected in idiosyncratic dispersion carries a lagged effect on bond prices in the same direction. In contrast, we do not observe such an effect for non-financial firms.

\subsection{Credit Ratings}

Default risk models and event studies document that bond prices respond to information differently according to firms' credit ratings (see, e.g., Griffin and Sanvicente (1982), and Holthausen and Leftwich (1986)). We divide our sample into two credit rating groups, A and $\mathrm{B}$, to investigate the ways by which bond prices of issuers in different credit ratings respond to firm-specific information. Group A consists of 5 largest commercial banks, 1 investment bank, 5 non-banks and 7 other non-financial firms whose credit ratings are at Aand above. Group B consists of 2 financial firms and 10 non-financial firms with credit ratings between $\mathrm{BB}$ and $\mathrm{BBB}+$. 
Panel A of Table 5 shows results for Group A that the coefficient on contemporaneous idiosyncratic dispersion is statistically insignificant, while the coefficient on the lagged idiosyncratic dispersion is positive and highly significant at the $1 \%$ level. In contrast, both the contemporaneous and the lagged idiosyncratic volatilities are not significantly associated with bond price changes. The overall pattern of these results is similar to those of financial firms, consistent with the market feature in Australia that financial firms generally receive high credit ratings.

The results for firms in group B, as shown in Panel B of Table 5, are similar, in that the lagged idiosyncratic dispersion is positive and highly significant at the $10 \%$ level. Again, idiosyncratic volatility does not exert significant influences on bond prices either in the week or in the following week of information arrival.

\subsection{Duration}

Bond durations have important implications on price sensitivities to various risks. In addition to interest rate risk, Collin-Dufresne et al. (2001) find that prices of corporate bonds with various maturities react differently to asset volatility. In this section, we further look into the patterns of price changes of bonds with different durations. We divide all the bonds into groups $\mathrm{A}, \mathrm{B}$ and $\mathrm{C}$, consisting of bonds with durations less than 3 years, 3 to 5 years, and 5 years or more, respectively.

Panel A of Table 6 reports results for group A that the coefficient estimates for the level and the slope of the term structure are insignificant, consistent with the intuition that interest rate risk is not a major concern for short duration bonds. Instead, both the contemporaneous and lagged idiosyncratic dispersions are important variables that show up 
with positive and statistically significant coefficient estimates. Idiosyncratic volatility and its lagged term, by contrast, show no significant relations with prices of short duration bonds.

The second group of bonds with durations ranging from 3 to 5 years represents the most common issues in the Australian bond market. As shown in Panel B of Table 6, both contemporaneous and the lagged idiosyncratic dispersions are positively associated with bond price changes. The effect of the contemporaneous idiosyncratic dispersion is statistically significant at the $5 \%$ level, and that of the lagged idiosyncratic dispersion is even more significant at the $1 \%$ level. Again, we do not find a significant relation between bond prices and idiosyncratic volatility, either contemporaneous or lagged.

For bonds with durations longer than 5 years, as shown in Panel $\mathrm{C}$ of Table 6, at the time the firm-specific information arrives, bond price changes are not significantly associated with contemporaneous idiosyncratic dispersion. The statistically significant coefficient on the lagged idiosyncratic dispersion shows that in the week following firmspecific information arrival, bond price changes are positively associated with the idiosyncratic dispersion.

Overall results suggest the patterns that prices of bonds with durations equal to or less than 5 years are associated with contemporaneous idiosyncratic dispersion, and that this effect persists in the next week following information arrival. For bonds with durations longer than 5 years, prices do not show immediate relation with contemporaneous idiosyncratic dispersion, but only respond significantly to the lagged idiosyncratic dispersion. 


\subsection{Leverage Ratio}

According to Merton (1974), a firm is close to default when its leverage ratio approaches one. Thus, the change in the firm's leverage ratio, an important factor related to default risk, may affect the ways by which bond prices respond to the arrival of firm-specific information. To investigate this issue, we sort the sample into two groups according to changes in firms' leverage ratios. We separate firms with decreasing leverage ratios over the sample period whose expected default risk has decreased from those firms with increasing leverage ratios.

For firms with decreasing leverage ratios, Panel A of Table 7, shows that bond prices positively and significantly respond to the lagged idiosyncratic dispersions, but not idiosyncratic volatility and the lagged idiosyncratic volatility. Panel B of Table 7 reports that bond prices of firms with increasing leverage ratios do not respond to idiosyncratic dispersion or idiosyncratic volatility, either contemporaneously or with a time lag. These results, taken together, suggest that bond prices of firms with decreasing leverage ratios are positively associated with the direction of idiosyncratic dispersion in the week following information arrival, but not the non-sign variation of the firm-specific idiosyncratic information.

\subsection{Market Capitalization}

Collin-Dufresne et al. (2001) find that a jump in the firm's market value increases credit spreads. We repeat the analysis by excluding those firms with decreasing market values. This is because the majority of bond issuers experienced increasing market capitalizations 
over the sample period. Table 8 shows, not surprisingly, very similar results to those of the whole sample shown in Table 3. It is clear that only the lagged idiosyncratic dispersion is positively and significantly associated with the changes in bond prices, while both contemporaneous and the idiosyncratic volatilities do not show significant associations with the change in bond prices.

\subsection{Market-to-Book Value Ratio}

Finally, we exam whether the relations between bond prices and idiosyncratic dispersion or idiosyncratic volatility may exhibit different patterns for firms with increasing or decreasing market-to-book equity ratios $(\mathrm{ME} / \mathrm{BE})$. We divide the sample firms into two groups based on whether their $\mathrm{ME} / \mathrm{BE}$ ratios were increasing or decreasing over the sample period.

Panel A of Table 9, for firms with increasing ME/BE ratios, shows that bond prices are positively and significantly associated with idiosyncratic dispersion in the week after information arrival. Consistent with our results earlier, the information content of idiosyncratic risk exhibits a same-direction effect on bond prices of firms with increasing $\mathrm{ME} / \mathrm{BE}$ ratios. These firms may be experiencing brighter business prospects (see, e.g., Fama and French (1993)). On the contrary, contemporaneous and the lagged idiosyncratic volatilities do not exhibit significant coefficient estimates. The results in Panel B of Table 9, for firms with decreasing $\mathrm{ME} / \mathrm{BE}$ ratios, show that bond price changes are not significantly associated with idiosyncratic dispersion or idiosyncratic volatility, either contemporaneous or with a lag. 


\section{Conclusions}

In this study we investigate the relations between bond price changes and the components of firm-specific idiosyncratic risk. We consider idiosyncratic dispersion which preserves the sign and idiosyncratic volatility that captures the magnitude of idiosyncratic risk, respectively. We then investigate whether the direction of idiosyncratic risk exhibits a relation with bond price changes. We also exam whether firm-level idiosyncratic volatility is accompanied with bond price changes. Notwithstanding the small sample, the preponderance of the evidence suggests that it is idiosyncratic dispersion carrying the direction of idiosyncratic risk that affects bond prices. In contrast, the magnitude of idiosyncratic risk does not exhibit such an effect.

Second, we find that bond price changes typically show a same-direction relation with idiosyncratic dispersion of share prices with a one-week lag, suggesting that bond investors take time to interpret information surprises contained in idiosyncratic risk. Moreover, we find that such an effect is most pronounced for certain types of bond issuers including: financial institutions, firms characterized by decreasing leverage ratio, increasing market capitalization, and increasing market-to-book ratio, all of which tend to be financially healthy and experiencing bright business prospects. Finally, bonds with shorter durations (equal to or less than 5 years) not only exhibit a same-direction, one-week lag in price changes, but also immediate price changes in the same direction with the idiosyncratic dispersion. 


\section{References}

Altman, E. I. and Kishore, V. M., (1998), Defaults and returns on high yield bonds: Analysis through 1997, NYU Salomon Center.

Ang, A, Hodrick, R., Xing, Y. and Zhang, X., (2006), The cross-section of volatility and expected returns, Journal of Finance 61, 259-299.

Bali, T. and Cakici, N., (2008), Idiosyncratic volatility and the cross-section of expected returns, Journal of Financial and Quantitative Analysis 43, 29-58.

Bali, T., Cakici, N., Zhe, Z., and Yan, X., (2005), Does idiosyncratic risk really matter?, Journal of Finance 60, 905-930.

Batten, J., Hogan, W., and Szilagyi, P., (2011), Financial market development and the role of foreign bond issuance: The case of Australia, Australian Economic Review 44, 3650.

Campbell, J., Lettau M, Malkiel, B. and Xu, Y., (2001), Have individual stocks become more volatile? An empirical exploration of idiosyncratic risk, Journal of Finance 56, 143.

Campbell, J. and Taksler, G., (2003), Equity volatility and corporate bond yields, Journal of Finance 58, 2321-2349.

Collin-Dufresne, P., Goldstein, R. and Martin, S., (2001), The determinants of credit spread changes, Journal of Finance 56, 2177-2207.

Creighton, A., Gower, L., and Richards, A., (2007), The impact of rating changes in Australian financial markets, Pacific-Basin Finance Journal, 15, 1-17

Debelle, G., (2011), The Australian bond market in 2011 and beyond, Reserve Bank of Australia, BIS Central Bankers' Speeches.

Duffee, G., (1998), The relation between treasury yields and corporate bond yield spreads, Journal of Finance 53, 2225-2241.

Duffie, D. and Singleton K., (1997), An econometric model of the term structure of interest-rate swap yields, Journal of Finance 52, 1287-1321.

Duffie, D. and Singleton K., (1999), Modeling term structures of defaultable bonds, Review of Financial Studies 12, 687-720.

Elton, E., Gruber, M., Agrawal, D. and Mann, C., (2001), Explaining the rate spread on corporate bonds, Journal of Finance 56, 247-278.

Fama, E., and French, K., (1993), Common risk factors in the returns on stocks and bonds, Journal of Financial Economics 33, 3-56. 
Fu, F., (2009), Idiosyncratic risk and the cross-section of expected stock returns, Journal of Financial Economics 91, 24-37.

Goyal A. and Santa-Clara, P., (2003), Idiosyncratic risk matters!, Journal of Finance 58, 975-1008.

Griffin, P. A. and Sanvicente, A. Z., (1982), Common stock returns and rating changes, Journal of Finance 37, 103-119.

Holthausen R. W. and Leftwich, R. W., (1986), "The effect of bond rating changes on common stock prices", Journal of Financial Economics 17, 57-89.

In, F., Brown, R. and Fang, V., (2003), The Australian and U.S. interest rate swaps markets: comparison and linkages, Accounting and Finance 44, 45-56.

Ince, O. and Porter, R., (2006), 'Individual Equity Return Data from Thomson Datastream: Handle with Care!', Journal of Financial Research 29, 463-479.

Ingersoll, J., (1977), A contingent-claims valuation of convertible securities, Journal of Financial Economics 4, 289-321.

Irvine, P.J., and Pontiff, J. (2009), Idiosyncratic return volatility, cash flows, and product market competition, Review of Financial Studies 22, 1149-1177.

Jarrow, R., and Turnbull, S., (1995), Pricing derivatives on financial securities subject to credit risk, Journal of Finance 50, 53-85.

Jones, E. P., Mason, S. and Rosenfeld, E., (1984), The contingent claims analysis of corporate capital structures: An empirical investigation, Journal of Finance 39, 611625.

Kwan, S., (1996), Firm-specific information and the correlation between individual stocks and bonds, Journal of Financial Economics 40, 63-80.

Longstaff, F., Mithal, S. and Neis, E., (2005), Corporate yield spreads: default risk or liquidity? New evidence from the credit-default swap market, Journal of Finance 60, 2213-2253.

Longstaff, F. and Schwartz, E., (1995), A simple approach to valuing risky fixed and floating rate debt, Journal of Finance 40, 789-819.

Merton, R. C., (1974), On the pricing of corporate debt: The risk structure of interest rates, Journal of Finance 29, 449-470.

Spiegel, M. and Wang, X., (2005), Cross-sectional variation in stock returns: Liquidity and idiosyncratic risk, Yale ICF Working Paper No. 05-13. 


\section{Figure 1 Australian Bonds Outstanding \% of GDP from 1991 to 2011.}

Monthly bond issued data are obtained from the Reserve Bank of Australia. The corporate bond issues have been substantially higher than government issues since June 2002. The government bond issues are rather constant between June 2001 and June 2007.

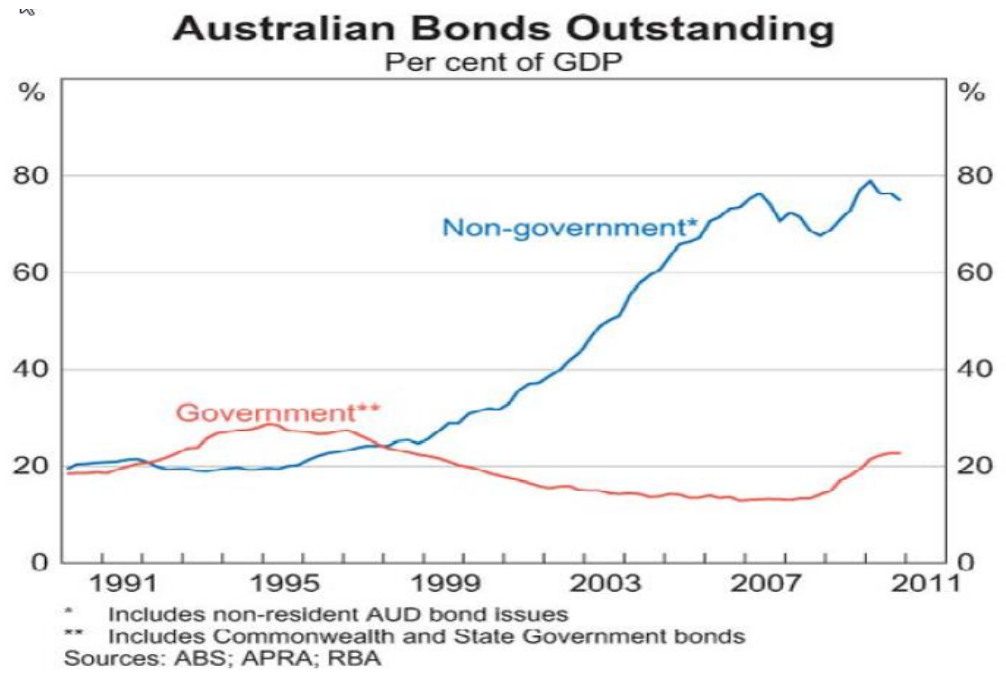

\section{Figure 2 Non Government Bond Outstanding}

The non-government debt market in Australia consists of four categories of issuers: financial institutions, other corporate issuers, asset-backed issuers and non-resident Kangaroo issuers.

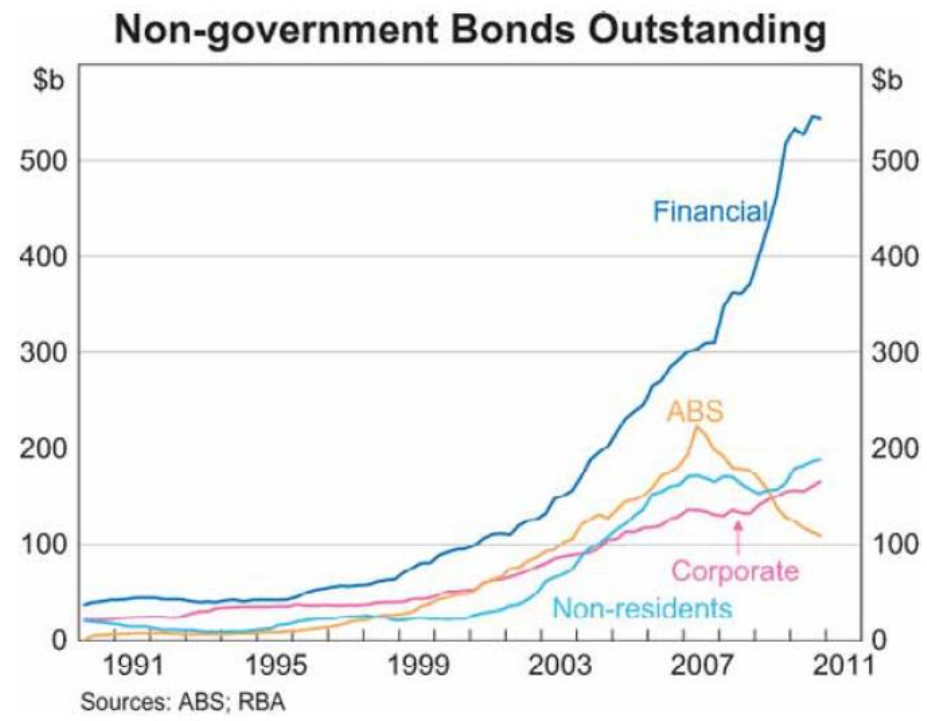




\section{Table 1: Industry Classification and rating Groups}

This table shows industry classifications and credit ratings of our bond sample, which covers six industry sectors: materials, energy, industrial, financial, consumer staples and utilities. We use S\&P long term debt rating to classify the bonds rating groups.

' $\mathrm{A}$ ' group includes bonds with ratings $\mathrm{A}+, \mathrm{A}$, and $\mathrm{A}-$, ' $\mathrm{BBB}$ ' group includes firms with $\mathrm{BBB}+, \mathrm{BBB}$, and $\mathrm{BBB}$ - ratings and 'BB' group includes firms with $\mathrm{BB}+$ and $\mathrm{BB}$, ratings.

\begin{tabular}{lc}
\hline & No of Bonds \\
\hline Whole sample & 117 \\
AA & 53 \\
A & 46 \\
BBB & 14 \\
BB & 4 \\
Consumer Staples & 18 \\
Energy & 3 \\
Financial & 81 \\
Industrial & 9 \\
Materials & 3 \\
Utility & 3 \\
\hline
\end{tabular}

\section{Table 2: Descriptive Statistics of Sample Bonds}

The table presents the characteristics and the distribution of sample bonds that were issued from July 1998 to June 2010. GIC sector is the global industrial classification under which the bond issuer is classified.

\begin{tabular}{lcccccc}
\hline GIC Sector & $\begin{array}{c}1 \text { to } 3 \\
\text { years }\end{array}$ & $\begin{array}{c}4 \text { to } 6 \\
\text { years }\end{array}$ & $\begin{array}{c}7 \text { years } \\
\text { and } \\
\text { above }\end{array}$ & $\begin{array}{c}\text { Less } \\
\text { than } \\
6 \%\end{array}$ & $\begin{array}{c}6 \% \text { to } \\
7 \%\end{array}$ & $\begin{array}{c}\text { Above } \\
7 \%\end{array}$ \\
\hline Consumer Staples & 1 & 14 & 3 & 2 & 10 & 6 \\
Energy & 1 & 2 & & & 3 & 13 \\
Financial & 18 & 41 & 22 & 23 & 45 & 5 \\
Industrial & & 3 & 6 & & 4 & 1 \\
Materials & & 3 & & & 2 & 3 \\
Utility & 20 & 65 & 32 & 25 & 67 & 25 \\
\hline Total & 20 & & & & & \\
\hline
\end{tabular}




\section{Table 3 All Issuers}

This table reports coefficient estimates for all sample firms of two regression models: Eqs. (3) and (6) for testing, respectively, the impacts of firm-specific idiosyncratic dispersion and idiosyncratic volatility on bond returns for the period from July 1998 to June 2010. Eq. (3) regresses the log price changes of individual bonds

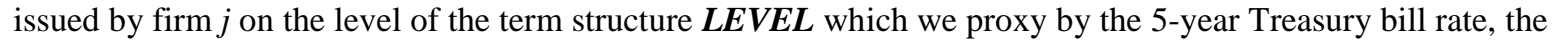
slope of the term structure $S \boldsymbol{L O P E}$ which we proxy by the difference between the 10- and 3-year Treasury bill rates, the liquidity premium $\boldsymbol{L I} \boldsymbol{Q}$ as measured by the difference between the 90 -day bank bill offer rate and the 13-week Treasury yield, the firm-specific idiosyncratic dispersion for firm $j \varepsilon_{j}$ and the one-period lag of the idiosyncratic dispersion; Eq. (6) differs from Eq. (3) only in the set of explanatory variables that include the idiosyncratic volatility for firm $j \boldsymbol{I V O} \boldsymbol{L}_{j}$ and its one-period lagged term to replace the contemporaneous and the one-period lagged $\varepsilon_{j}$. All variables are in weekly frequency. $* * * * *$ and $*$ refer to statistical significance at the levels of $1 \%, 5 \%$ and $10 \%$, respectively.

Panel A: All Firms

\begin{tabular}{|c|c|c|c|}
\hline \multicolumn{2}{|c|}{ Equation (3) } & \multicolumn{2}{|c|}{ Equation (6) } \\
\hline Explanatory Variables & Coefficients & Explanatory Variables & Coefficients \\
\hline Constant & $\begin{array}{l}0.0017 \\
(1.61)\end{array}$ & Constant & $\begin{array}{l}0.0018 \\
(1.73)^{*}\end{array}$ \\
\hline Bond Index Return & $\begin{array}{l}0.5448 \\
(9.36)^{* * *}\end{array}$ & Bond Index Return & $\begin{array}{l}0.5433 \\
(9.21)^{* * *}\end{array}$ \\
\hline Level of the Term Structure & $\begin{array}{l}-0.0004 \\
(-2.4)^{* *}\end{array}$ & Level of the Term Structure & $\begin{array}{l}-0.0005 \\
(-3.09)^{* *}\end{array}$ \\
\hline Slope of the Term Structure & $\begin{array}{l}0.0001 \\
(0.41)\end{array}$ & Slope of the Term Structure & $\begin{array}{l}0.0001 \\
(0.02)\end{array}$ \\
\hline Liquidity Premium & $\begin{array}{l}0.0010 \\
(1.95)^{*}\end{array}$ & Liquidity Premium & $\begin{array}{l}0.0014 \\
(2.41)^{* *}\end{array}$ \\
\hline Idiosyncratic Dispersion & $\begin{array}{l}0.0023 \\
(1.16)\end{array}$ & Idiosyncratic Volatility & $\begin{array}{l}0.0230 \\
(0.77)\end{array}$ \\
\hline $\begin{array}{l}\text { One-Period Lagged } \\
\text { Idiosyncratic Dispersion }\end{array}$ & $\begin{array}{l}0.0060 \\
(4.28)^{* * *}\end{array}$ & $\begin{array}{l}\text { One-Period Lagged } \\
\text { Idiosyncratic Volatility }\end{array}$ & $\begin{array}{l}0.0009 \\
(0.03)\end{array}$ \\
\hline $\begin{array}{l}\text { Number of Bonds } \\
\text { Number of Observations }\end{array}$ & $\begin{array}{l}117 \\
24145\end{array}$ & & \\
\hline
\end{tabular}




\section{Table 4 Issuer Type}

This table reports coefficient estimates of two regression models: Eqs. (3) and (6) for testing, respectively, the impacts of firm-specific idiosyncratic dispersion and idiosyncratic volatility on bond returns for the period from July 1998 to June 2010. Eq. (3) regresses the log price changes of individual bonds issued by firm $j$ on

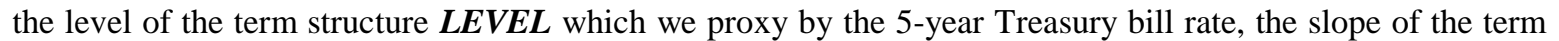
structure SLOPE which we proxy by the difference between the 10- and 3-year Treasury bill rates, the liquidity premium $\boldsymbol{L I Q}$ as measured by the difference between the 90-day bank bill offer rate and the 13-week Treasury yield, the firm-specific idiosyncratic dispersion for firm $j \varepsilon_{j}$ and the one-period lag of the idiosyncratic dispersion; Eq. (6) differs from Eq. (3) only in the set of explanatory variables that include the idiosyncratic volatility for firm $j \boldsymbol{I V O \boldsymbol { L } _ { j }}$ and its one-period lagged term to replace the contemporaneous and the one-period lagged $\varepsilon_{j}$. All variables are in weekly frequency. $* * * * *$ and $*$ refer to statistical significance at the levels of $1 \%, 5 \%$ and $10 \%$, respectively. Panels A and B report results for non-financial and financial firms, respectively.

Panel A: Financial firms

\begin{tabular}{|c|c|c|c|}
\hline \multicolumn{2}{|c|}{ Equation (3) } & \multicolumn{2}{|c|}{ Equation (6) } \\
\hline Explanatory Variables & Coefficients & Explanatory Variables & Coefficients \\
\hline Constant & $\begin{array}{r}0.0007 \\
(0.44)\end{array}$ & Constant & $\begin{array}{l}0.0010 \\
(0.73)\end{array}$ \\
\hline Bond Index Return & $\begin{array}{c}0.5750 \\
(7.92)^{* * *}\end{array}$ & Bond Index Return & $\begin{array}{c}0.5743 \\
(7.79)^{* * *}\end{array}$ \\
\hline Level of the Term Structure & $\begin{array}{l}-0.0003 \\
(-1.05)\end{array}$ & Level of the Term Structure & $\begin{array}{l}-0.0004 \\
(-1.56)\end{array}$ \\
\hline Slope of the Term Structure & $\begin{array}{l}0.0004 \\
(0.95)\end{array}$ & Slope of the Term Structure & $\begin{array}{l}0.0003 \\
(0.65)\end{array}$ \\
\hline Liquidity Premium & $\begin{array}{c}0.0009 \\
(2.16)^{* *}\end{array}$ & Liquidity Premium & $\begin{array}{c}0.0010 \\
(2.10)^{* *}\end{array}$ \\
\hline Idiosyncratic Dispersion & $\begin{array}{l}0.0028 \\
(1.13)\end{array}$ & Idiosyncratic Volatility & $\begin{array}{l}0.0160 \\
(0.40)\end{array}$ \\
\hline $\begin{array}{l}\text { One-Period Lagged } \\
\text { Idiosyncratic Dispersion }\end{array}$ & $\begin{array}{c}0.0087 \\
(5.26)^{* * *}\end{array}$ & $\begin{array}{l}\text { One-Period Lagged } \\
\text { Idiosyncratic Volatility }\end{array}$ & $\begin{array}{l}-0.0008 \\
(-0.02)\end{array}$ \\
\hline $\begin{array}{l}\text { Number of Bonds } \\
\text { Number of Observations }\end{array}$ & $\begin{array}{c}81 \\
15,501\end{array}$ & & \\
\hline
\end{tabular}




\section{Table 4 (continued)}

\begin{tabular}{lccc}
\hline & \multicolumn{2}{c}{ Panel B: Non-financial firms } & \\
\hline Constant & 0.0042 & Constant & 0.0036 \\
& $(3.30)^{* * *}$ & & $(2.57)^{* *}$ \\
Bond Index Return & 0.4795 & Bond Index Return & 0.4766 \\
& $(4.91)^{* * *}$ & & $(4.89)^{* * *}$ \\
Level of the Term Structure & -0.0009 & Level of the Term Structure & -0.0010 \\
& $(-3.77)^{* * *}$ & & $(-3.99)^{* * *}$ \\
Slope of the Term Structure & -0.0004 & Slope of the Term Structure & -0.0006 \\
& $(-1.44)$ & & $(-1.79)^{*}$ \\
Liquidity Premium & 0.0014 & Liquidity Premium & 0.0022 \\
& $(0.95)$ & & $(1.49)$ \\
Idiosyncratic Dispersion & 0.0011 & Idiosyncratic Volatility & 0.0380 \\
& $(0.35)$ & & $(0.96)$ \\
One-Period Lagged & 0.0003 & One-Period Lagged & 0.0046 \\
Idiosyncratic Dispersion & $(0.11)$ & Idiosyncratic Volatility & $(0.12)$ \\
& & & \\
\hline & & & \\
\hline Number of Bonds & 36 & & \\
\hline
\end{tabular}




\section{Table 5 Credit Rating}

This table reports coefficient estimates of two regression models: Eqs. (3) and (6) for testing, respectively, the impacts of firm-specific idiosyncratic dispersion and idiosyncratic volatility on bond returns for the period from July 1998 to June 2010. Eq. (3) regresses the log price changes of individual bonds issued by firm $j$ on the level of the term structure $L E V E L$ which we proxy by the 5-year Treasury bill rate, the slope of the term structure SLOPE which we proxy by the difference between the 10- and 3-year Treasury bill rates, the liquidity premium $L I Q$ as measured by the difference between the 90 -day bank bill offer rate and the 13-week Treasury yield, the firm-specific idiosyncratic dispersion for firm $j \varepsilon_{j}$ and the one-period lag of the idiosyncratic dispersion; Eq. (6) differs from Eq. (3) only in the set of explanatory variables that include the idiosyncratic volatility for firm $j I V O L_{j}$ and its one-period lagged term to replace the contemporaneous and the one-period lagged $\varepsilon_{j}$. All variables are in weekly frequency. $* * *, * *$ and $*$ refer to statistical significance at the levels of $1 \%, 5 \%$ and $10 \%$, respectively. Panels A and B report results for firms with credit ratings at A and above and firms with credit ratings between $\mathrm{B}$ and $\mathrm{A}$, respectively.

Panel A. Credit rating: A

\begin{tabular}{lclc}
\hline \multicolumn{2}{c}{ Equation (3) } & \multicolumn{2}{c}{ Equation (6) } \\
\hline Explanatory Variables & Coefficients & Explanatory Variables & Coefficients \\
\hline Constant & 0.0018 & Constant & 0.0019 \\
& $(1.45)$ & & $(1.66)^{*}$ \\
Bond Index Return & 0.5577 & Bond Index Return & 0.5574 \\
& $(8.81)^{* * *}$ & & $(8.69)^{* * *}$ \\
Level of the Term Structure & -0.0004 & Level of the Term Structure & -0.0006 \\
& $(-2.24)^{* *}$ & & $(-2.82)^{* * *}$ \\
Slope of the Term Structure & 0.0003 & Slope of the Term Structure & 0.0002 \\
& $(0.85)$ & & $(0.58)$ \\
Liquidity Premium & 0.0008 & Liquidity Premium & 0.0011 \\
& $(2.12)^{* *}$ & & $(2.66)$ \\
Idiosyncratic Dispersion & 0.0025 & Idiosyncratic Volatility & 0.0300 \\
& $(1.15)$ & & $(0.9)$ \\
One-Period Lagged & 0.0061 & One-Period Lagged & -0.0106 \\
Idiosyncratic Dispersion & $(3.89)^{* * *}$ & Idiosyncratic Volatility & $(-0.34)$ \\
& & & \\
& & & \\
\hline Number of Bonds & 99 & & \\
Number of Observations & 20,505 & & \\
\hline
\end{tabular}




\section{Table 5 (continued)}

Panel B. Credit rating: B

\begin{tabular}{lclc}
\hline \multicolumn{2}{c}{ Equation (3) } & \multicolumn{2}{c}{ Equation (6) } \\
\hline Explanatory Variables & Coefficients & Explanatory Variables & Coefficients \\
\hline Constant & 0.0017 & Constant & 0.0012 \\
& $(0.72)$ & & $(0.49)$ \\
Bond Index Return & 0.4687 & Bond Index Return & 0.4610 \\
& $(3.03)^{* * *}$ & & $(3.01)^{* * *}$ \\
Level of the Term Structure & -0.0004 & Level of the Term Structure & -0.0006 \\
& $(-0.86)$ & & $(-1.25)$ \\
Slope of the Term Structure & -0.0009 & Slope of the Term Structure & -0.0012 \\
& $(-1.91)^{*}$ & & $(-2.65)$ \\
Liquidity Premium & 0.0026 & Liquidity Premium & 0.0034 \\
Idiosyncratic Dispersion & $(0.85)$ & & $(1.03)$ \\
One-Period Lagged & 0.0008 & Idiosyncratic Volatility & -0.0184 \\
Idiosyncratic Dispersion & $(0.18)$ & & $-0.29)$ \\
& 0.0058 & One-Period Lagged & 0.0686 \\
& $(1.81)^{*}$ & Idiosyncratic Volatility & $(0.98)$ \\
& & & \\
\hline Number of Bonds & & & \\
Number of Observations & 18 & & \\
\hline
\end{tabular}




\section{Table 6 -Duration}

This table reports coefficient estimates of two regression models: Eqs. (3) and (6) for testing, respectively, the impacts of firm-specific idiosyncratic dispersion and idiosyncratic volatility on bond returns for the period from July 1998 to June 2010. Eq. (3) regresses the log price changes of individual bonds issued by firm $j$ on the level of the term structure $\boldsymbol{L E} \boldsymbol{V E \boldsymbol { L }}$ which we proxy by the 5-year Treasury bill rate, the slope of the term structure SLOPE which we proxy by the difference between the 10- and 3-year Treasury bill rates, the liquidity premium $\boldsymbol{L I} \boldsymbol{Q}$ as measured by the difference between the 90 -day bank bill offer rate and the 13-week Treasury yield, the firm-specific idiosyncratic dispersion for firm $j \varepsilon_{j}$ and the one-period lag of the idiosyncratic dispersion; Eq. (6) differs from Eq. (3) only in the set of explanatory variables that include the idiosyncratic volatility for firm $j \boldsymbol{I V O \boldsymbol { L } _ { j }}$ and its one-period lagged term to replace the contemporaneous and the one-period lagged $\varepsilon_{j}$. All variables are in weekly frequency. $* * *, * *$ and $*$ refer to statistical significance at the levels of $1 \%, 5 \%$ and $10 \%$, respectively. Panels A, B and C report results for firms that issue bonds with duration less than 3 years, between 3 and 5 years and greater than 5 years, respectively.

Panel A: Firms that issue bonds with duration less than 3 years

\begin{tabular}{lclc}
\hline \multicolumn{2}{c}{ Equation (3) } & \multicolumn{2}{c}{ Equation (6) } \\
\hline Explanatory Variables & Coefficients & Explanatory Variables & Coefficients \\
\hline Constant & 0.0008 & Constant & -0.0003 \\
& $(0.77)$ & & $(-0.26)$ \\
Bond Index Return & 0.4696 & Bond Index Return & 0.4713 \\
& $(4.69)^{* * *}$ & & $(4.71)^{* * *}$ \\
Level of the Term Structure & -0.0002 & Level of the Term Structure & -0.0002 \\
& $(-1.40)$ & & $(-0.96)$ \\
Slope of the Term Structure & -0.0003 & Slope of the Term Structure & -0.0001 \\
& $(-1.36)$ & & $(-0.35)$ \\
Liquidity Premium & 0.0002 & Liquidity Premium & -0.0002 \\
Idiosyncratic Dispersion & $(0.27)$ & & $(-0.28)$ \\
One-Period Lagged & 0.0036 & Idiosyncratic Volatility & 0.0230 \\
Idiosyncratic Dispersion & $(1.83)^{*}$ & & $(1.13)$ \\
& 0.0033 & One-Period Lagged & -0.0072 \\
& $(1.69)^{*}$ & Idiosyncratic Volatility & $(-0.31)$ \\
& & & \\
\hline Number of Bonds & & & \\
Number of Observations & 2,322 & & \\
\hline
\end{tabular}




\section{Table 6 (continued)}

Panel B: Firms that issue bonds with duration between 3 years and 5 years

\begin{tabular}{lclc}
\hline Constant & 0.0051 & Constant & 0.0049 \\
& $(4.89)^{* * *}$ & & $(4.35)$ \\
Bond Index Return & 0.3895 & Bond Index Return & 0.3864 \\
& $(6.07)^{* * *}$ & & $(6.05)^{* * *}$ \\
Level of the Term Structure & -0.0010 & Level of the Term Structure & -0.0011 \\
& $(-5.28)^{* * *}$ & & $(-5.57)^{* * *}$ \\
Slope of the Term Structure & -0.0007 & Slope of the Term Structure & -0.0009 \\
& $(-2.55)^{* *}$ & & $(-3.14)^{* * *}$ \\
Liquidity Premium & 0.0012 & Liquidity Premium & 0.0017 \\
& $(1.56)$ & & $(2.07)^{* *}$ \\
Idiosyncratic Dispersion & 0.0050 & Idiosyncratic Volatility & 0.0381 \\
& $(2.22)^{* *}$ & & $(1.23)$ \\
One-Period Lagged & 0.0055 & One-Period Lagged & -0.0060 \\
Idiosyncratic Dispersion & $(3.34)^{* * *}$ & Idiosyncratic Volatility & $(-0.18)$ \\
& & & \\
\hline & 65 & & \\
Number of Bonds & 10,972 & & \\
Number of Observations & & & \\
\hline
\end{tabular}

Panel C: Firms that issue bonds with duration greater than 5 years

\begin{tabular}{lclc}
\hline Constant & -0.0006 & Constant & -0.0000 \\
& $(-0.27)$ & & $(-0.01)$ \\
Bond Index Return & 0.7436 & Bond Index Return & 0.7426 \\
& $(6.48)^{* * *}$ & & $(6.34)^{* * *}$ \\
Level of the Term Structure & -0.0001 & Level of the Term Structure & -0.0003 \\
& $(-0.33)$ & & $(-0.77)$ \\
Slope of the Term Structure & 0.0010 & Slope of the Term Structure & 0.0001 \\
& $(1.65)$ & & $1.32)$ \\
Liquidity Premium & 0.0014 & Liquidity Premium & 0.0018 \\
& $(1.34)$ & & $-1.65)$ \\
Idiosyncratic Dispersion & -0.0020 & Idiosyncratic Volatility & -0.0203 \\
& $(-0.44)$ & & $(-0.29)$ \\
One-Period Lagged & 0.0089 & One-Period Lagged & 0.0397 \\
Idiosyncratic Dispersion & $(2.80)^{* *}$ & Idiosyncratic Volatility & $(0.63)$ \\
& & & \\
\hline & 32 & & \\
Number of Bonds & 10,813 & & \\
Number of Observations & & & \\
\hline
\end{tabular}




\section{Table 7 Leverage Ratio}

This table reports coefficient estimates of two regression models: Eqs. (3) and (6) for testing, respectively, the impacts of firm-specific idiosyncratic dispersion and idiosyncratic volatility on bond returns for the period from July 1998 to June 2010. Eq. (3) regresses the log price changes of individual bonds issued by firm $j$ on the level of the term structure $\boldsymbol{L E} \boldsymbol{V E \boldsymbol { L }}$ which we proxy by the 5-year Treasury bill rate, the slope of the term structure SLOPE which we proxy by the difference between the 10- and 3-year Treasury bill rates, the liquidity premium $\boldsymbol{L I Q}$ as measured by the difference between the 90-day bank bill offer rate and the 13week Treasury yield, the firm-specific idiosyncratic dispersion for firm $j \varepsilon_{j}$ and the one-period lag of the idiosyncratic dispersion; Eq. (6) differs from Eq. (3) only in the set of explanatory variables that include the idiosyncratic volatility for firm $j \boldsymbol{I V O \boldsymbol { L } _ { j }}$ and its one-period lagged term to replace the contemporaneous and the one-period lagged $\varepsilon_{j}$. All variables are in weekly frequency. $* * *, * *$ and $*$ refer to statistical significance at the levels of 1\%, 5\% and 10\%, respectively. Panels A and B report results for firms with increasing and decreasing leverage ratios, respectively.

Panel A. Decreasing leverage ratio

\begin{tabular}{lclc}
\hline \multicolumn{2}{c}{ Equation (3) } & \multicolumn{2}{c}{ Equation (6) } \\
\hline Explanatory Variables & Coefficients & Explanatory Variables & Coefficients \\
\hline Constant & 0.0015 & Constant & 0.0016 \\
& $(1.05)$ & & $(1.14)$ \\
Bond Index Return & 0.5371 & Bond Index Return & 0.5345 \\
& $(7.41)^{* * *}$ & & $(7.27)^{* * *}$ \\
Level of the Term Structure & -0.0004 & Level of the Term Structure & -0.0005 \\
& $(-1.82)^{*}$ & & $(-2.31)^{* *}$ \\
Slope of the Term Structure & 0.0004 & Slope of the Term Structure & 0.0003 \\
& $(0.91)$ & & $(0.69)$ \\
Liquidity Premium & 0.0019 & Liquidity Premium & 0.0023 \\
Idiosyncratic Dispersion & $(2.68)^{* * *}$ & & $(2.80)^{* * *}$ \\
One-Period Lagged & 0.0021 & Idiosyncratic Volatility & 0.0002 \\
Idiosyncratic Dispersion & $(0.75)$ & & $(0.00)$ \\
& 0.0080 & One-Period Lagged & 0.0213 \\
& $(4.38)^{* * *}$ & Idiosyncratic Volatility & $(0.51)$ \\
& & & \\
\hline Number of Bonds & & & \\
Number of Observations & 13,786 & & \\
\hline
\end{tabular}




\section{Table 7 (continued)}

Panel B. Increasing leverage ratio

\begin{tabular}{lclc}
\hline \multicolumn{2}{c}{ Equation (3) } & \multicolumn{2}{c}{ Equation (6) } \\
\hline Explanatory Variables & Coefficients & Explanatory Variables & Coefficients \\
\hline Constant & 0.0022 & Constant & 0.0022 \\
& $(1.24)$ & & $(1.34)$ \\
Bond Index Return & 0.5562 & Bond Index Return & 0.5565 \\
& $(5.66)^{* * *}$ & & $(5.63)^{* * *}$ \\
Level of the Term Structure & -0.0005 & Level of the Term Structure & -0.0006 \\
& $(-1.56)$ & & $(-2.03)^{* *}$ \\
Slope of the Term Structure & -0.0002 & Slope of the Term Structure & -0.0004 \\
& $(-0.53)$ & & $(-0.89)$ \\
Liquidity Premium & -0.0003 & Liquidity Premium & 0.0001 \\
Idiosyncratic Dispersion & $(-0.39)$ & & $(0.10)$ \\
One-Period Lagged & 0.0026 & Idiosyncratic Volatility & 0.0568 \\
Idiosyncratic Dispersion & $(0.98)$ & & $(1.54)$ \\
& 0.0031 & One-Period Lagged & -0.0294 \\
& $(1.44)$ & Idiosyncratic Volatility & $(-0.85)$ \\
& & & \\
\hline Number of Bonds & & & \\
\hline
\end{tabular}




\section{Table 8 Market Capitalization}

This table reports coefficient estimates of two regression models: Eqs. (3) and (6) for testing, respectively, the impacts of firm-specific idiosyncratic dispersion and idiosyncratic volatility on bond returns for the period from July 1998 to June 2010. Eq. (3) regresses the log price changes of individual bonds issued by firm $j$ on

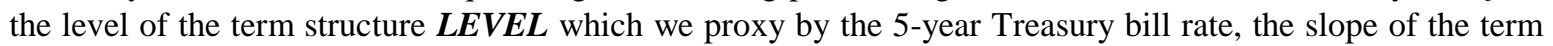
structure SLOPE which we proxy by the difference between the 10- and 3-year Treasury bill rates, the liquidity premium $\boldsymbol{L I} \boldsymbol{Q}$ as measured by the difference between the 90-day bank bill offer rate and the 13-week Treasury yield, the firm-specific idiosyncratic dispersion for firm $j \varepsilon_{j}$ and the one-period lag of the idiosyncratic dispersion; Eq. (6) differs from Eq. (3) only in the set of explanatory variables that include the idiosyncratic volatility for firm $j \boldsymbol{I V O \boldsymbol { L } _ { j }}$ and its one-period lagged term to replace the contemporaneous and the one-period lagged $\varepsilon_{j}$. All variables are in weekly frequency. $* * *, * *$ and $*$ refer to statistical significance at the levels of $1 \%, 5 \%$ and $10 \%$, respectively.

Increasing market capitalization

\begin{tabular}{lclc}
\hline \multicolumn{2}{c}{ Equation (3) } & \multicolumn{2}{c}{ Equation (6) } \\
\hline Explanatory Variables & Coefficients & Explanatory Variables & Coefficients \\
\hline Constant & 0.0019 & Constant & 0.0020 \\
& $(1.60)$ & & $(1.77)$ \\
Bond Index Return & 0.5615 & Bond Index Return & 0.5602 \\
& $(9.24)^{* * *}$ & & $(9.11)^{* * *}$ \\
Level of the Term Structure & -0.0005 & Level of the Term Structure & -0.0006 \\
& $(-2.41)^{* *}$ & & $(-3.11)^{* *}$ \\
Slope of the Term Structure & 0.0001 & Slope of the Term Structure & 0.0004 \\
& $(0.53)$ & & $(0.12)$ \\
Liquidity Premium & 0.0012 & Liquidity Premium & 0.0017 \\
Idiosyncratic Dispersion & $(2.39)^{* *}$ & & $(2.84)^{* * *}$ \\
One-Period Lagged & 0.0026 & Idiosyncratic Volatility & 0.0260 \\
Idiosyncratic Dispersion & $(1.21)$ & & $(0.80)$ \\
& 0.0064 & One-Period Lagged & -0.0015 \\
& $(4.32)^{* * *}$ & Idiosyncratic Volatility & $(-0.05)$ \\
& & & \\
\hline Number of Bonds & & & \\
\hline
\end{tabular}




\section{Table 9 Market-to-Book Ratio}

This table reports coefficient estimates of two regression models: Eqs. (3) and (6) for testing, respectively, the impacts of firm-specific idiosyncratic dispersion and idiosyncratic volatility on bond returns for the period from July 1998 to June 2010. Eq. (3) regresses the log price changes of individual bonds issued by firm $j$ on the level of the term structure $\boldsymbol{L E} \boldsymbol{V E \boldsymbol { L }}$ which we proxy by the 5-year Treasury bill rate, the slope of the term structure SLOPE which we proxy by the difference between the 10- and 3-year Treasury bill rates, the liquidity premium $\boldsymbol{L I Q}$ as measured by the difference between the 90-day bank bill offer rate and the 13-week Treasury yield, the firm-specific idiosyncratic dispersion for firm $j \varepsilon_{j}$ and the one-period lag of the idiosyncratic dispersion; Eq. (6) differs from Eq. (3) only in the set of explanatory variables that include the idiosyncratic volatility for firm $j \boldsymbol{I V O \boldsymbol { L } _ { j }}$ and its one-period lagged term to replace the contemporaneous and the one-period lagged $\varepsilon_{j}$. All variables are in weekly frequency. $* * * * *$ and $*$ refer to statistical significance at the levels of $1 \%, 5 \%$ and $10 \%$, respectively. Panels A and B report results for firms with increasing and decreasing market capitalizations, respectively.

Panel A. Increasing market-to-book ratio

\begin{tabular}{lclc}
\hline \multicolumn{2}{c}{ Equation (3) } & \multicolumn{2}{c}{ Equation (6) } \\
\hline Explanatory Variables & Coefficients & Explanatory Variables & Coefficients \\
\hline Constant & 0.0027 & Constant & 0.0022 \\
& $(1.97)^{* *}$ & & $(1.52)$ \\
Bond Index Return & 0.4694 & Bond Index Return & 0.4692 \\
& $(7.61)^{* * *}$ & & $(7.55)^{* * *}$ \\
Level of the Term Structure & -0.0006 & Level of the Term Structure & -0.0007 \\
& $(-2.70)^{* * *}$ & & $(-2.89)^{* * *}$ \\
Slope of the Term Structure & 0.0001 & Slope of the Term Structure & -0.0001 \\
& $(0.06)$ & & $(-0.26)$ \\
Liquidity Premium & 0.0007 & Liquidity Premium & 0.0010 \\
Idiosyncratic Dispersion & $(1.31)$ & & $(1.55)$ \\
One-Period Lagged & 0.0010 & Idiosyncratic Volatility & 0.0423 \\
Idiosyncratic Dispersion & $(0.40)$ & & $(1.39)$ \\
& 0.0021 & One-Period Lagged & -0.0103 \\
& $(1.96)^{* *}$ & Idiosyncratic Volatility & $(-0.33)$ \\
& & & \\
\hline Number of Bonds & & & \\
Number of Observations & 7822 & & \\
\hline
\end{tabular}




\section{Table 9 (continued)}

\section{Panel B. Decreasing market-to-book ratio}

\begin{tabular}{lclc}
\hline \multicolumn{2}{c}{ Equation (3) } & \multicolumn{2}{c}{ Equation (6) } \\
\hline Explanatory Variables & Coefficients & Explanatory Variables & Coefficients \\
\hline Constant & 0.0013 & Constant & 0.0016 \\
& $(0.11)$ & & $(0.14)$ \\
Bond Index Return & 0.5797 & Bond Index Return & 0.5777 \\
& $(0.83)$ & & $(0.82)$ \\
Level of the Term Structure & -0.0004 & Level of the Term Structure & -0.0005 \\
& $(-0.17)$ & & $(-0.24)$ \\
Slope of the Term Structure & 0.0002 & Slope of the Term Structure & 0.0001 \\
& $(0.05)$ & & $(0.01)$ \\
Liquidity Premium & 0.0011 & Liquidity Premium & 0.0016 \\
Idiosyncratic Dispersion & $(0.18)$ & & $(0.23)$ \\
One-Period Lagged & 0.0029 & Idiosyncratic Volatility & 0.0140 \\
Idiosyncratic Dispersion & $(0.13)$ & & $(0.04)$ \\
& 0.0078 & One-Period Lagged & 0.0061 \\
& $(0.45)$ & Idiosyncratic Volatility & $(0.02)$ \\
& & & \\
\hline Number of Bonds & 80 & & \\
Number of Observations & 16,323 & & \\
\hline
\end{tabular}

